\title{
Is the NZEB benchmarking approach suitable for assessing energy retrofit design?
}

\author{
Marco Beccali ${ }^{1, a}$, Alessandra Galatioto ${ }^{1, b}$, Giuliana Leone $e^{1, c}$ \\ and Sonia Longo ${ }^{1, d}$
}

\author{
${ }^{1}$ Dep. DEIM, Università degli Studi di Palermo, Viale delle Scienze - Bldg 9, 90128 Palermo - Italy \\ amarco.beccali@dream.unipa.it, ${ }^{\mathrm{b}}$ alessandra.galatioto@dream.unipa.it, 'giuliana.leone@unipa.it, \\ dsonialongo@dream.unipa.it
}

Keywords: NZEB evaluation, energy retrofit, building refurbishment

\begin{abstract}
Currently, many effort have been done to enable energy saving issues in building design and many definitions have been introduced for most performing constructions based on energy balance between energy demand and supply. Recently, the Net Zero Energy Building theory has bypassed old Passive House concept but many questions still remain open. Present work aims to estimate how NZEB requirements matching could be affected by the choice of their definition and the choice of weighting factor system, to be count in the energy balance. NZEB concept is mainly referred to new buildings design. Its application to existing buildings is for sure an hard task provided the architecture and physical constraints are often problematic. Nevertheless, the benchmarking approach able to assess the building performance according to the NZEB objective can be utilized for other two purposes. The first one is to assess how an existing building is far from the performances of a NZEB. The second one is to assess the contribution of a conventional retrofit in improving its energy balance.
\end{abstract}

\section{Introduction}

Overview. Recently worldwide climatic changes have been focusing attention on energy saving necessity and a lot of effort has been made to enable this issue, both at research and legislative level. Hence, architectural and technological design has become an important field to be investigated in order to improve new building energy performance; while many legislative codes have been introduced at local level and more (for example in EU the EPBD codes introduced by Directive 2002/91/EC and Directive 2010/31/EU) [1]. Thus, many researches have been carried out on these topics but few efforts have been made on existing buildings which represent at least the main part of worldwide building stock. However, the latter roles an important play in energy saving issues, especially in Italy, where areas earmarked for new building construction have been continuously reduced? Within that category, recently survey shows how the energy consumption in public existing buildings has a very high impact. Moreover energy refurbishment is often a hard-to-achieve goal, due to both technical and legislative barriers: best practices focus on plant and envelope energy performance, respectively at active and passive design level. Hence, the optimal compromise between energy demand and supply is the most important issue to achieve.

NZEB theory. A first approach to the energy saving topics lead to Passive House concept that was centered on energy demand reduction to almost zero values and stand-alone energy supply. Moreover recent researches have moved towards new directions aiming to balance energy demand by renewable energy sources supply, in a defined period and in a grid connected system from whom the "net" term. Moreover this new approach contains within itself some points of indeterminacy related to its definition. Which is the physical boundary limit of the system to count on? Could it be only the building footprint or a large suitable area could be included? And how large it could be? Which are the terms to be included in the balance? Moreover, which is the best compromise between demand reduction and energy supply? Is it possible to dismiss energy efficiency at building design level in favor of only plant design? Which is the most suitable metric to be used in such a balance? From these questions different NZEB definitions have been sorted. For example, Torcellini et al. in 2006 [2] 
distinguished among: Net Zero Site Energy, Net Zero Source Energy, Net Zero Energy Cost and Net Zero Energy Emission. The four definitions differ for the chosen boundary (with spatial or technological approaches) and for metrics (energy unit for the first two, money or emission metric for the latest two). This introduces a critical aspect in the balance evaluation that is related to the choice of appropriated weighting factors. Indeed, they can merely be intended as conversion factors from final to primary energy or when they embed numerical weights they must be utilized to take into account strategic or policy issues (Fig.1). Moreover, it is worth noting that NZEB concept is almost focused on new building construction neglecting energy refurbishment [3-5].
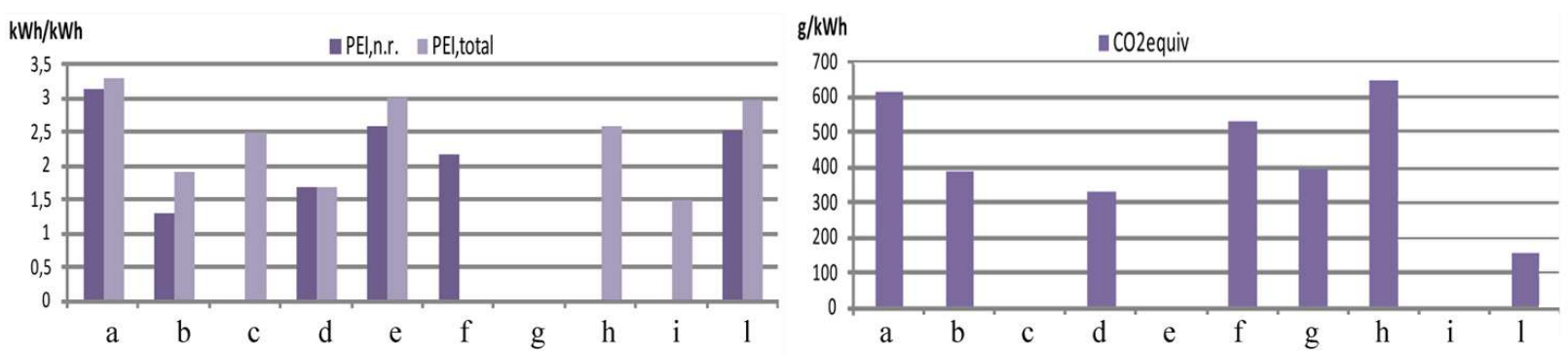

Fig. 1. Comparison among conversion factors for different Countries and local codes.PEI: Primary Energy Indicator $\left(\mathrm{kWh}\right.$ primary $\left./ \mathrm{kWh}_{\text {delivered }}\right)$; PEI,n.r.: non renewable part $\left(\mathrm{kWh}_{\text {primary }} / \mathrm{kWh}_{\text {delivered }}\right)$; $\mathrm{CO}_{\text {2equiv. }}$ : equivalent $\mathrm{CO}_{2}$ emissions ( $\mathrm{g} / \mathrm{kWh}_{\text {delivered }}$ ). On the x-axis: a. EN 15603:2008 Europe; b. GEMIS Vers.4.5, Austria; c. BR 2010, Denmark; d. BC 2012, Finland; e. DIN V 18599/1, Germany; f. UNI TS 11300/4, Italy; g. NS 3700, Norway; h. Calener2009, Spain; i. EN 15316, Sweden; 1. SIA 2031, Switzerland.

Research target. As already highlighted, building refurbishment is an important goal to be achieved due to its weight on energy worldwide consumption even if many design and technical limit exits. So that how long the net zero energy target in building refurbishment is feasible at a legislative and technical level? Which role the choice of the definition and the weighting factors could have?

\section{Methodology}

In order to evaluate how different definitions and set of weighting factors could change an assessment of NZEB related performance and what is the main suitable for refurbishment evaluation, a real study case has been introduced. It deals with the building "Facoltà di Biologia" located in the Campus of University of Palermo (South Italy). The $7,000 \mathrm{~m}^{2} \mathrm{NE} / \mathrm{SO}$ oriented building is placed nearby a parking lot and it belongs to ' $70 \mathrm{~s}$, its volume is $47152 \mathrm{~m}^{3}$ while the $\mathrm{S} / \mathrm{V}$ ratio value is 0,23 . Window area is about $35 \%$ of the total vertical surfaces. Laboratories, classroom and offices are located and connected each other by large hallway spaces. Furthermore an experimental campaign and an electrical consumption audit have been done in order to evaluate actual building energy performance. Finally the all year round occupation pattern has been taken into consideration, so as also internal loads have been estimated.
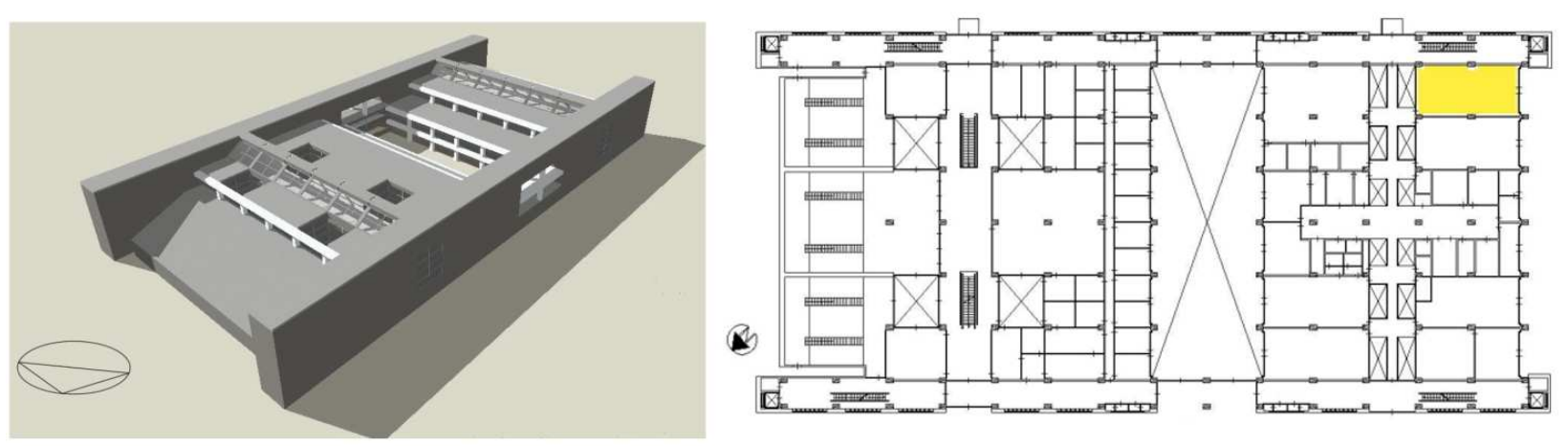

Fig. 2 Case-study building model and plant: "Facoltà di Biologia" in Palermo. 
Afterwards, a base case-study has been analyzed by means of Energy Plus simulation software [4] in order to assess the building energy performance in a time-dependent simulation. Specifically consumption has been estimated sorting some representative area for each intended use and were compared to the gathered data from survey. Thus, considering the general energy saving issues, some refurbishment scenarios have been introduced. According to a NZEB approach philosophies a PV system has been firstly introduced considering the available surfaces for a good architectonical integration and were taken as constant features in all the others scenario. So that the following models have been performed by means of Energy-plus model [5]:

- Scenario 1. Considering the available surfaces, a PV system has been added to the base study-case, with $39.20 \mathrm{MWh} / \mathrm{y}$, corresponding to $3.2 \mathrm{kWh}_{\mathrm{e}} / \mathrm{m}^{2} \mathrm{y}$ electrical production by the installed power $35.02 \mathrm{~kW}_{\mathrm{p}}$ with an efficiency equal to $15 \%$.

- Scenario 2. According to local code, insulation materials have been introduced in order to improve building opaque envelope thermal resistance. Five centimeters fiber-glass panel was used for wall insulation changing U-value from 0.48 to $0.39 \mathrm{~W} / \mathrm{m}^{2} \mathrm{~K}$, while roof surface was covered by a PU (10 $\mathrm{cm}$ ) improving U-value to $0.38 \mathrm{~W} / \mathrm{m}^{2} \mathrm{~K}$.

- Scenario 3. A new HVAC plant has been introduced on the base case-study with a mechanical ventilation efficiency sets to $85 \%$ and an reversible heat pump characterized by mean seasonal efficiency equal to 3.5 and 3.2 respectively in winter and summer. Distribution losses are 6\%;

- Scenario 4. This scenario includes all the previous scenarios, moreover introducing higher efficiency window whose transmittance value is $2.1 \mathrm{~W} / \mathrm{m}^{2} \mathrm{~K}$ with selective glasses;

- Scenario 5. This scenario includes the previous one adding a step-control in lighting system considering the daylighting;

- Scenario 6. This scenario includes the previous one adding a continuous-control in lighting system considering the daylighting.

Finally, all these results were implemented in the NZEB Evaluation Tool created by IEA Task-40 [6]. The tool is structured in three spread sheets: the first one is aimed to describe building feature and plant production distinguishing different loads (cooling, heating, DHW, lighting, plug load, auxiliaries and ventilation) from monitored or estimated consumption by on or off site generation, setting apart by energy carriers. The second spreadsheet takes into account the weighting factor that could be assumed as static all over the year or on monthly base; finally the third spreadsheet introduces operating cost for generated and delivered energy. The tool output is the energy balance according to the main four NZEB definition: NZEB primary, NZEB limited, NZEB carbon and NZEB cost. In particular, cooling, heating, lighting loads have been introduced and PV production was set to $39.20 \mathrm{MWh} / \mathrm{y}$, while conversion factors were introduced as static weighting factor for each scenario and for different National codes. The Cost definition was not considered due to the lack of information; while the other three were compared with each other and for each country.

\section{Results and discussion}

Energy refurbishment. The base case-study simulation gave a yearly average consumption of $33.8 \mathrm{kWh} / \mathrm{m}^{2} \mathrm{y}$ and all the introduced scenario allow a reduction of this consumption. The first three scenario show how isolated actions at opaque envelope and plant generation/production levels do not affect energy balance significantly. For example, reducing opaque envelope U-value lead to an energy saving about $15 \%$ with respect to the base study-case even in Summer and Winter. Thus the need to join all these refurbishment action in scenario 4 considering also window energy performance. Important results concern the last scenario where a consumption decreases about $64 \%$ and $78.9 \%$ of the balance with respect to base case-study are recorded introducing respectively a stepped and continuous control lighting system. Specifically, the Scenario 6 is the better one in terms of CO2 emission reduction about $509.421 \mathrm{~kg} / \mathrm{y}$.

NZEB definition impact: Italy. Comparing results in Fig.3 a considerable gap is recorded in the balance values between the two energy-based NZEB definition: for the first three scenario, primary NZEB results are about 2 times higher than the limited ones, this trend increases to 3 times in the next 
scenario. A more constant trend is recorded for the emission-based definition (NZEB Carbon) where an average reduction about $20 \%$ is recorded with respect to the base study-case.

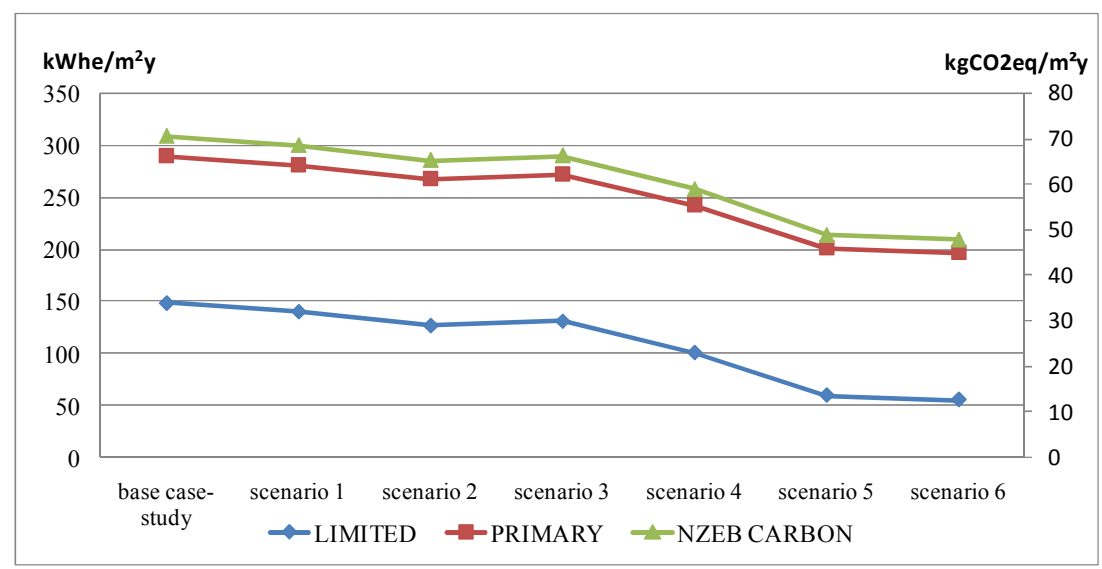

Fig. 3 Comparison among different NZEB energy balances for each refurbishment scenario.

NZEB weighting factor impact: a comparison between Country code. Weighting factors were evaluated Country by Country taking into account primary conversion factors in order to assess their affection on energy balance [7-15]. As shown in Fig. 4, changing values in accordance with Fig. 1 leads to very different results in the balance. In accordance with energy-based definitions the best results correspond to Switzerland whose balance was about 2 times the one of Sweden, corresponding to the lowest energy balance scenario. Higher gap is recorded in the NZEB graph where the less performing Spain matches a 4 times higher value with respect to the most performing Switzerland.
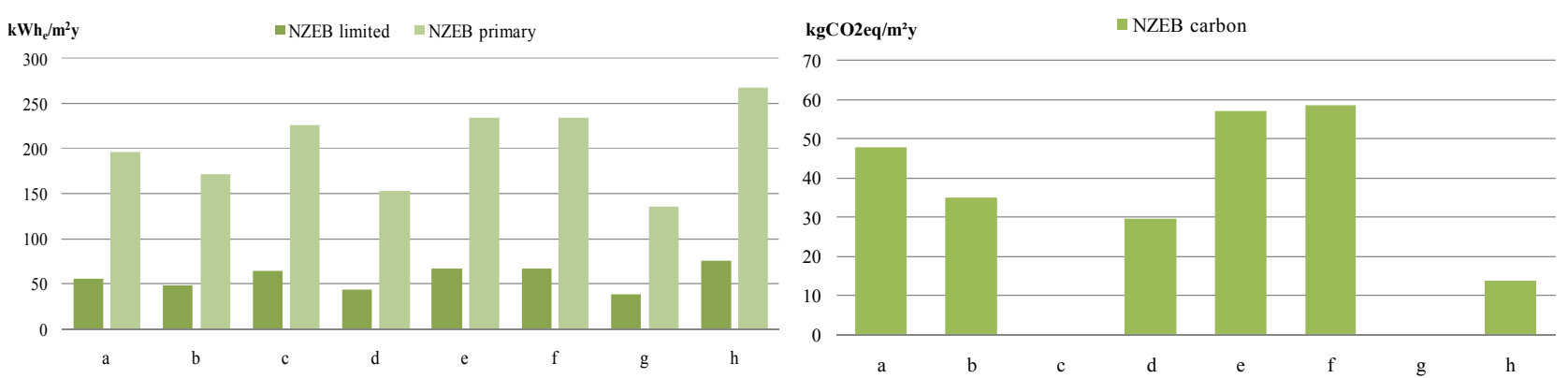

Fig. 4 Scenario 6: comparison among energy balances weighting factors from different codes in the best scenario. On x-axis: a. Italy; b. Austria; c. Denmark; d. Finland; e. Germany, f. Spain; g. Sweden; h. Switzerland.

The best scenario (scenario 6) was implemented, neglecting architectonical integration, and other PV surfaces covering the whole roof area $\left(\sim 3250 \mathrm{~m}^{2}\right)$ are provided. PV plant design was carried out considering the available surface, the best orientation, PV module efficiency and shadowing effect; $18,70 \mathrm{kWh} / \mathrm{m}^{2} \mathrm{y}$ PV production was estimated. This further scenario was performed according to Italian Code. Fig. 5 shows how better results are achieved for all three definitions, among which the Limited one is the most suitable. 


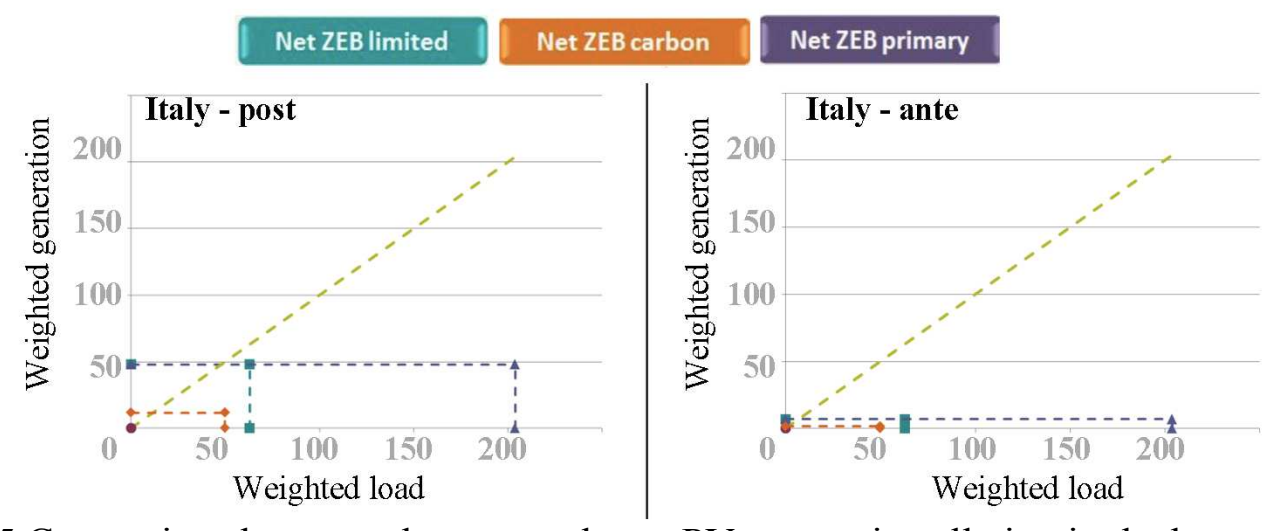

Fig. 5 Comparison between the ante and post PV system installation in the best scenario

\section{Conclusion}

The present work demonstrates how NZEB target for existing buildings is hard to achieve goal. Reducing the energy losses and enhancing the HVAC efficiency, throughout retrofit, are not enough to match NZEB requirements, according to the introduced definitions. So, appropriate area has to be found within the building and/or its outdoor spaces in order to improve the energy production by renewable source. According to our results and for NZEB Limited definition, the better balance is suitable to achieve the Zero target. Moreover, political decisions are necessary for easy finding available surface according to legislative code or strategic actions which have to be introduced at territorial level. It has to be noticed that public buildings are more suitable for NZEB matching as their outdoor spaces are suitable for energy production; moreover energy sources could be easily displaced nearby. Finally, the further development of this work will concern deepening of energy zero target in building refurbishment in order to find out design criteria suitable in this topic.

\section{References}

[1] EPBD recast, Directive 2010/31/EU of the European Parliament and of the Council of 19 May 2010 on the energy performance of buildings (recast), Official Journal of the European Union, (2010).

[2] P. Torcellini, S. Pless, M. Deru and D. Crawley: Zero Energy Buildings. A Critical Look at the Definition, proceeding of Conference Paper NREL/CP-550-39833, June 2006.

[3] I. Sartori, A. Napolitano, K. Vossc: Net zero energy buildings: A consistent definition framework, Energy Buildings (2012), doi:10.1016/j.enbuild.2012.01.032, in press.

[4] M. Cellura, G. Ciulla, V. Lo Brano, A. Orioli, L. Campanella, F. Guarino, D. Nardi Cesarini: The redesign fan Italian building to reach net zero energy performances: a case study of SHC task $40-$ ECBCS Annex 52, (ML-11-C040), ASHRAE Transaction, Volume 117, Part 2

[5] M. Cellura, L. Campanella, G. Ciulla, F. Guarino, V. Lo Brano, D. Nardi Cesarini, A. Orioli, A Net Zero Energy Building in Italy: Design Studies to Reach the Net Zero Energy Building Performance Simulation Association "Driving better design through simulation". An IBPSA AIRAH Conference, Sydney, Australia, 14-16 November.

[6] EnergyPlus 7.2.0. http://apps1.eere.energy.gov/buildings/energyplus.

[7] M. Beccali, A. Galatioto, J. Galletto, Proposte per il risparmio energetico negli edifici pubblici: Edificio 16 di Parco d'Orleans Palermo, Proceedings of $65^{\circ}$ Congresso Nazionale ATI, Cagliari 2010.

[8] Information on http://task40.iea-shc.org/net-zeb 
[9] DIN EN 15603:2008, Energy performance of buildings - Overall energy use and definition of energy ratings; German version EN 15603:2008

[10] EN 15603:2008 Energy Performance of Buildings - Overall energy use and definition of energy rations - Annex E Factors and coefficients, CEN.

[11]Database of GEMIS, Internet page of the program: http://www.oeko.de/service/gemis/en/Denmark*2015. The Danish Building Code 2010, BR 2010.

[12] National Building Code of Finland. Part D3 Energy- Efficiency. Ministry of Environment 201.

[13] NS 3700 (2010) Criteria for passive houses and low energy buildings -residential buildings, Standards Norway.

[14] DIN V 18599:2007, Energy efficiency of buildings - Calculation of the net, final and primary energy demand for heating, cooling, ventilation, domestic hot water and lighting - Part 1: General balancing procedures, terms and definitions, zoning and evaluation of energy carriers.

[15] UNI-TS 11300-4:2012, Energy performance of buildings - Part 4: Renewable energy and other generation systems for space heating and domestic hot water production. 